\title{
OsWDRP3, a WD-40 repeat protein interacts with OsBAK1 to control leaf angle by modulating BR signaling
}

Lei Zhang ( $\square$ arabilab@whu.edu.cn )

Wuhan University

Di Xi

Xinyang College

Zi-Ying Wang

Wuhan University

Chen-Jie Long

Wuhan University

\section{Research Article}

Keywords: WD40 protein, leaf angle, brassinosteroid, signal transduction, protein degradation

Posted Date: February 1st, 2022

DOI: https://doi.org/10.21203/rs.3.rs-1306537/v1

License: (c) (i) This work is licensed under a Creative Commons Attribution 4.0 International License.

Read Full License 


\section{Abstract}

Leaf angle is an essential component of plant architecture. Brassinosteroids (BRs) plays important roles in regulating leaf angle. WD-40 repeat proteins (WDRPs) act as versatile scaffolds for protein-protein interactions and participate in plant growth and development. To date, the functions of OsWDRPs have been largely unknown. Here, we found that OsWDRP3 regulates leaf angle through the BR pathway in rice. qRT-PCR and GUS reporter assays revealed that OsWDRP3 was expressed in a variety of tissues, especially leaves. OsWDRP3 predominantly resides in the cytoplasm and aggregates near the cell membrane. OsWDRP3-RNAi plants exhibited less sensitivity to BR than the wild type. Using bimolecular fluorescence complementation assays and Co-IP, we determined that OsWDRP3 interacts physically with OsBAK1. More importantly, an in vitro cell-free degradation assay showed that OsWDRP3 participates in the protein degradation of OsBAK1. We also found that the degradation of OsBAK1 was delayed in OsWDRP3 RNAi plants. In conclusion, our data suggest that OsWDRP3 affects BR signaling by regulating the concentration of OsBAK1 in the cytoplasm and thus regulating the leaf angle in rice.

\section{Background}

Leaf angle is an essential component of plant architecture and plays important les in breeding yields (Sinclair and Sheehy 1999; Xu et al. 2021). Recent analysis has shown that a complex network participates in the regulation of leaf angle, and protein kinases and hormones, especially brassinosteroids (BRs), play important roles in this network (Zhou et al. 2017; Li et al. 2020; Xu et al. 2021). Loss-of-function mutants of BR biosynthesis genes show erect leaves (Hong et al. 2002, 2003, 2005; Sakamoto et al. 2006; Tanabe et al. 2005). OsHAP3E regulates leaf angle by inhibiting BR biosynthesis (Ito et al. 2011). In addition, SLENDER GRAIN (SLG), as a positive regulator of BR synthesis, participates in the regulation of lamina joint angle (Feng et al. 2016). BU1, D1/RGA1, ILI1, OsBRI1, DLT, OsBAK1, OsBZR1 and TUD1, as BR signaling components, also positively regulate leaf angle in rice (Bai et al. 2007; Hu et al. 2013; Li et al. 2009; Tanaka et al. 2009; Tong et al. 2012; Wang et al. 2006; Zhao et al. 2013; Ruan et al. 2018). Some BR signaling factors, such as GSK2, IBH1 and OsLIC, negatively regulate the leaf angle in rice (Tong et al. 2012; Zhang et al. 2009; Wang et al. 2008).

Several other identified BR-related genes participate in the regulation of leaf angle. OFP3 is an interactor of both GSK2 and DLT. It has been reported that OFP3-overexpressing lines show reduced plant height, leaf angle and grain size (Xiao et al. 2020). Biochemical and genetic assays demonstrated that GSK2 phosphorylates WRKY53 and lowers its stability. WRKY53 has also been shown to interact with BZR1. Genetic evidence shows that WRKY53 functions in a common pathway with the MAPKKK10-MAPKK4MAPK6 cascade in leaf angle and seed size control (Tian et al. 2021). Certain MADS genes, such as OsMADS55, OsMADS22 and OsMDP1, which are negative regulators in BR signaling, negatively regulate lamina joint bending (Lee et al. 2008; Duan et al. 2006). LC2 is a BR-induced gene that regulates lamina joint bending by affecting cell division (Zhao et al. 2010). A number of other genes positively regulate lamina joint bending, such as SDG725, OsGRAS19, RGA, SCR and XIAO (Sui et al. 2012; Chen et al. 2013; Lin et al. 2019; Jiang et al. 2012). A positive regulator of BR signaling, reduced leaf angle 1 (RLA1), 
physically interacts with OsBZR1 and then regulates leaf angle in rice (Qiao et al. 2017; Hirano et al. 2017). Some bHLH transcription factors, such as OsBLR1, participate in leaf angle regulation though the BR pathway in rice (Wang et al. 2020). Similarly, gain-of-function OsbHLH079 also causes a wide leaf angle, while OsbHLH079-RNAi lines show the opposite phenotype (Seo et al. 2020). OsBUL1 positively affects leaf angles by controlling cell elongation (Jang et al. 2017). Recently, Guo et al. (2021) demonstrated that OsbHLH98 negatively regulates leaf angle by regulating the transcription of OsBUL1. Therefore, BR biosynthesis and signaling greatly influence the rice leaf angle.

WD40 repeat proteins have an approximately 40 amino acid core region. The $\mathrm{N}$-terminus of the core region contains a glycine-histidine (GH) dipeptide, and the C-terminus has a tryptophan-aspartate (WD) dipeptide (Migliori et al. 2012). The sequences of WD40 proteins are poorly conserved, and their functions are diverse (Jain and Pandey 2018). The WD40 protein family has been identified using genome-wide identification in Arabidopsis (van Nocker et al. 2003), cotton (Salih et al. 2018), foxtail millet (Mishra et al. 2014), rice (Ouyang et al. 2012), wheat (Hu et al. 2018), humans (Zou et al. 2018), peach (Feng et al. 2019) and mango (Tan et al. 2021). The functions of some WD proteins have been revealed. Three WD40 proteins, i.e., LEUNIG homolog (LUH), FRAGILE FIBER3 (FRA3) and TWD40-2, are associated with cell wall formation (Bui et al. 2011; Zhong et al. 2004; Bashline et al. 2015). Another three WD40 proteins, i.e., CYP71, HOS15 and MS11, are associated with gene regulation (Li et al. 2007; Zhu et al. 2008; Mehdi et al. 2016). ULCS1, a WD40 protein in Arabidopsis, participates in the degradation of various proteins by interacting with the E3 ligase complex (Beris et al. 2016). Another Arabidopsis WD40 protein, i.e., NEDD, plays a role in microtubule organization (Zeng et al. 2009). The WD repeat-containing protein TTG1 has functions in the immune response (Zhao et al. 2008). Therefore, studying the function of WD40 proteins is of great significance for further understanding the regulatory mechanism of plant development.

To date, there are approximately 200 putative WD40 proteins in rice (Ouyang et al. 2012). However, the roles of most WD40 proteins remain unknown. In this paper, we found that a WD40 protein in rice was involved in the regulation of leaf upright growth, and RNAi transgenic plants showed BR insensitivity. In vitro degradation results showed that the degradation of OsBAK1 was delayed in RNAi transgenic plants, which inhibited BR signal transduction. This study provides insights into the roles of OsWDRP3 in the BR pathway.

\section{Results}

\section{OsWDRP3-RNAi knockdown transgenic plants display erect leaves}

To investigate the biological function of OsWDRP3, an OsWDRP3 mutant ( $w d r p 3,2 A-20340)$ was isolated from a T-DNA insertion library with the cv Dongjin background (Jeon et al. 2000; Jeong et al. 2006). $w d r p 3$ plants were short with a small leaf angle, but the number of seeds was very small; thus, we developed OsWDRP3-overexpressing and OsWDRP3-silenced lines to characterize the roles of OsWDRP3 
in rice plants. Over 20 independent T0 OsWDRP3 RNAi lines were obtained. We then selected the RNAi14 line with the lowest OsWDRP3 gene expression to analyze the gene functions (Fig. 1A). We also generated transgenic rice plants overexpressing OsWDRP3 (OE) under the control of a maize ubiquitin promoter. The expression level of OsWDRP3 was higher in OE line 9 than in wild-type plants. We selected OE line 9 to analyze the phenotype (Fig. 1B). In this study, all the transgenic lines, including the OE and RNAi lines, were in the background of Hejiang19, a japonica variety.

OsWDRP3-RNAi lines showed a reduction in plant height (to $70 \%-75 \%$ of the wild-type height, $\mathrm{n}=15, \mathrm{P}<$ 0.01). OsWDRP3-OE plants were slightly higher than the wild ones, but there was no significant difference (Fig. 1C). Internode elongation was inhibited in all of the RNAi plants. We measured the lengths of the individual internodes of plants. The results showed that each internode of OsWDRP3-RNAi plants had a different length than the wild type. The first, second, third and fourth internodes were shortened by $17 \%$, $41 \%, 48 \%$ and $53 \%$, respectively (Fig. 1D). Based on the proportion of each internode to the total internode length, OsWDRP3-RNAi plants belong to type D6 dwarfism, which is usually related to BR synthesis or signal transduction correlation (Takeda 1974). Additionally, although the plant height of the overexpressed transgenic plants was similar to that of the wild type, its internode length changed, in which the first internode extended relative to the wild type. It was $39 \%$ longer in the first internode, $2 \%$ shorter in the second, $43 \%$ shorter in the third and $88 \%$ shorter in the fourth compared with the wild type. Some overexpressed transgenic plants did not even have the fourth internode.

In wild-type rice, the leaf blade bends away from the vertical axis of the leaf sheath, whereas the leaves of OsWDRP3-RNAi seedlings were erect at the seedling and adult stages (Fig. 1). The second lamina joint angle of 9-day-old wild-type seedlings was $17.49 \pm 4.09^{\circ}$, whereas that of the OsWDRP3-RNAi was $5.80 \pm 1.63^{\circ}$ (Fig. 1E), representing a 3 -fold increase in the lamina angles of wild-type relative to that of the OsWDRP3-RNAi plants. At the heading and harvest stages, the flag leaf angle, second leaf angle and third leaf angle of OsWDRP3-RNAi plants were reduced by $36 \%, 28 \%$ and $32 \%$, respectively, compared with the wild type (Fig. 1F). Since BR regulates the bending of the lamina joint (Yamamuro et al. 2000; Hong et al. 2003), these results suggest that OsWDRP3 may be involved in BR biosynthesis or signal transduction in rice.

\section{OsWDRP3 participates in the regulation of BR synthesis and transduction}

We checked the expression of OsWDRP3 in wild-type rice under BR treatment by quantitative PCR. Seven DAG wild-type rice seedlings were treated with $1 \mu \mathrm{M}$ 24-epibrassinolide (24-eBL, the active $\mathrm{BL}$ ), and leaves treated with $0 \mathrm{~h}, 2 \mathrm{~h}, 4 \mathrm{~h}, 8 \mathrm{~h}, 12 \mathrm{~h}$ and $24 \mathrm{~h}$ were extracted. Total RNA was extracted, and cDNA was synthesized by reverse transcription in vitro. OsWDRP3 gene expression increased after 2 $\mathrm{h}$ of treatment with $1 \mu \mathrm{M} 24-\mathrm{eBL}$ and decreased after $4 \mathrm{~h}$ of treatment (Fig. $2 \mathrm{~A}$ ). The results showed that BR induced OsWDRP3 gene expression, suggesting that the OsWDRP3 gene may be involved in the BR signaling pathway. 
BR biosynthesis and signal transduction are modulated in an intricate manner in plants (Tanaka 2005). OsBRI1 and OsBZR1 have been identified, and their loss-of-function mutants display erect leaves (Yamamuro et al. 2000; Bai et al. 2007). OsBZR1 directly regulates the expression of the DWARF AND LOW TILLERING (DLT) gene, an important BR response factor in rice (Tong et al. 2009). To investigate whether OsWDRP3 was involved in the BR signaling pathway, we examined the expression of BR-related genes in wild type and OsWDRP3-RNAi. The expression of OsBRI1 was downregulated in wild-type plants under BR treatment, which was consistent with a previous report (Yamamuro et al. 2000). In RNAi transgenic plants, the expression of OsBRI1 was downregulated, and there was little change in the expression level after BR treatment. The results also showed that the BR signaling pathway regulation gene OsBAK1 upregulated expression in wild-type plants under BR treatment. Additionally, the expression of OsBAK1 was upregulated in RNAi plants but decreased after BR treatment, which was different from wild-type plants. The expression levels of BZR1, which plays positive roles in BR signaling, were upregulated when BR treatment was applied to wild-type plants, but no significant change occurred in OsWDRP3-RNAi plants (Fig. 2B).

We therefore analyzed the expression of BR biosynthetic genes in WT and OsWDRP3-RNAi (Tanabe et al. 2005; Hong et al. 2003). It was previously shown that the expression of CPD, which is involved in $B R$ biosynthesis, is downregulated by BL treatment (Tanaka et al. 2005). Hence, the expression level of CPD can be used as an indicator of BL perception. We studied the effect of eBL on the expression of BRspecific biosynthetic genes in wild-type and OsWDRP3-RNAi plants. When the plants were treated with $\mathrm{eBL}$, the expression of these genes in the wild-type plants was visibly reduced but not affected in OsWDRP3-RNAi plants (Fig. 2C).

qRT-PCR results suggested that BR signal transduction was impaired in the OsWDRP3-RNAi plants. BR signaling represses BR synthesis in a negative feedback manner, and impaired BR signaling usually promotes the transcript accumulation of BR biosynthesis genes (Bai et al. 2007; Tong et al. 2009). These results suggest that OsWDRP3 might be a positive regulator in the BR signaling pathway.

\section{OsWDRP3-RNAi plants show BR-insensitive phenotypes}

To examine whether the leaf-bending morphology of OsWDRP3-RNAi was related to BR signaling, we tested the effect of exogenous BR on wild-type plants and RNAi plants.

First, we examined the coleoptile elongation of wild-type and OsWDRP3-RNAi seedlings in response to eBL. Rice seeds were germinated in MS medium in the dark with or without $1 \mu \mathrm{M} \mathrm{eBL}$. In wild-type plants, coleoptile elongation was promoted when $1 \mu \mathrm{M}$ eBL was added to the medium, but the same experimental phenomenon was not seen in OsWDRP3-RNAi plants (Fig. 3A).

Second, we tested the response of root growth of the wild-type and OsWDRP3-RNAi seedlings to eBL. In the absence of eBL, the root growth of OsWDRP3-RNAi plants was obviously shorter than that of the wild 
type. (Fig. $3 \mathrm{~B}$ ). In the presence of $1 \mu \mathrm{M}$ eBL, root elongation in wild-type seedlings was inhibited, whereas OsWDRP3-RNAi showed the same growth status before and after treatment (Fig. 3B).

eBL can promote bending at the lamina joint, and BR-deficient and BR-insensitive mutants show decreased bending of the lamina joint (Cao and Chen 1995; Tanabe et al. 2005). We analyzed the sensitivity of OsWDRP3-RNAi and OsWDRP3-OE to eBL with a lamina joint assay (Yamamuro et al. 2000). The lamina inclination assay revealed that the OsWDRP3-RNAi plants displayed an insensitive phenotype to BR. After treatment with $100 \mathrm{nM}$ 24-eBL, the second lamina joint angle of the 7-day-old wildtype and OsWDRP3-RNAi seedlings increased by $8.12 \pm 0.18$ and $4.83 \pm 0.14$ times, respectively (Fig. 3C). The lamina angles of wild-type plants increased significantly after eBL treatment, whereas those of OsWDRP3-RNAi had no obvious response. There was no significant difference between OsWDRP3-OE and wild-type plants (Fig. 3C).

These results suggested that the OsWDRP3-RNAi seedlings were less sensitive to exogenous BR than wild-type seedlings.

\section{OsWDRP3 is a WD40 repeat protein and widely express in rice}

The deduced amino acid sequence of OsWDRP3 consists of 345 residues. The primary sequence contains seven WD40 domains, one WDxR motif and one putative DWD box (Fig. 4A). WD40 domains often fold into the most ideal and stable seven-bladed $\beta$-propellers with a funnel-like shape (Jain and Pandey 2018). We analyzed the WD40 domain in OsWDRP3 (https://swissmodel.expasy.org/). There were seven WD40 repeat domains and a funnel-like shape, as displayed in Figure 1A. This result suggests that OsWDRP3 may be involved in intracellular protein interactions similar to other WD40 proteins.

Comparison of amino acid sequences indicated that OsWDRP3 shared high identities with three WD repeat proteins in Arabidopsis (At3g15610, 79\% sequence identity; At1g52730, 79\% sequence identity; At1g15470/XIW1, 74\% sequence identity) (Fig. 4B). These data clearly suggested that OsWDRP3 is one of the closest relatives of WD repeat proteins in Arabidopsis.

We performed RT-qPCR assays using total RNA from various tissues of plants at the seedling stage and reproductive stage, including panicles, different internodes, nodes, leaf blades, leaf sheaths, and roots. OsWDRP3 expression was detected in all tissues examined but primarily in dividing tissues, including the uppermost internode, node, and leaf sheath. The abundance of transcripts encoding OsWDRP3 was highest in the internode at 60 days after germination (DAG) and lower in the seedling, stem and lamina joints of the japonica rice variety Hejiang19 (Fig. 5A).

To analyze the expression pattern of OsWDRP3 in detail, we cloned a 2-kb promoter region of OsWDRP3 to drive the GUS gene and then transformed rice plants. GUS staining was observed in various organs in 
transgenic plants. Overall, the histochemical staining results showed that OsWDRP3 expressed in most tissues throughout plant growth and development. A high level of expression was primarily observed in the root, pollen and internodes (Fig. 5B). We examined the lamina joint region, leaf blade and sheath in 9d-old transgenic seedlings (Fig. 5B). The veins in the leaf blade and sheath were well stained (Fig. 5B). In the reproductive stage, staining was observed in the vascular bundles of the lemma and palea in particular (Fig. 5B), and the anther was also stained (Fig. 5B). Thus, OsWDRP3 functions throughout plant growth and development.

To investigate the subcellular localization of OsWDRP3, we constructed a pUbi::OsWDRP3-GFP construct. We observed the fluorescence of the OsWDRP3-GFP fusion protein and found that GFP was distributed in the cytoplasm (Fig. 5C), indicating cytoplasmic localization of OsWDRP3.

\section{OsWDRP3 interacts with OsBAK1 and regulates its degradation in rice}

Based on the bioinformatics analysis, OsWDRP3 is a serine-threonine kinase receptor-associated protein. Combined with the previous phenotypic analysis results, we speculated that OsWDRP3 might interact with BR-related serine-threonine kinases.

Brassinosteroid insensitive 1 (BRI1) is the BR receptor in plants. BRI1 heteromerizes with BRI1-associated kinase 1 (BAK1) and forms a receptor complex to activate BR signaling. We chose OsBRI1 and OsBAK1 to analyze the interactions with OsWDRP3.

To determine whether WDRP3 and BAK1 or BRI1 interact in plant cells, we performed bimolecular fluorescence complementation (BiFC) in Agrobacterium tumefaciens-infiltrated tobacco (N. benthamiana) and rice protoplasts. We fused WDRP3 to the N-terminal yellow fluorescent protein (YFP) fragment (OsWDRP3-N-YFP) and the intracellular kinase region of OsBAK1 (BAK1K) or OsBRI1 (BRI1K) to the Cterminal YFP fragment (BAK1K-C-YFP, BRI1K-C-YFP). In control experiments, WDRP3-NYFP coexpressed with unfused C-YFP or unfused N-YFP coexpressed with BAK1K-C-YFP (Fig. $6 \mathrm{~A}$ and $B)$. When fused WDRP3-N-YFP was coexpressed with BAK1K-C-YFP in tobacco leaves or rice protoplasts, fluorescence signals were detected in transformed cells (Fig. $6 \mathrm{~A}$ and $\mathrm{B}$ ), but no signal was detected in WDRP3-N-YFP/BRI1K-C-YFP coexpressed cells.

OsBAK1-GFP fusion protein is principally located on the plasma membrane. However, OsBAK1-GFP was abundant in the cytoplasm during plasmolysis experiments and distributed in a spot-like way (Li et al., 2009). This result suggested that BAK1 might break off above the membrane and enter the cytoplasm under treatment conditions. Our BiFC results showed that OsBAK1 was also localized in the cytoplasm when it interacted with OsWDRP3 in rice protoplasts (Fig. 6B).

Coimmunoprecipitation assays showed that OsWDRP3 interacts with OsBAK1 in planta. Rice seedling leaves isolated from the Ubi::OsWDRP3-Myc transgene plant were ground in protein extraction 
buffer. After centrifugation, the supernatant was used as a total protein extract. Protein extracts (input) were immunoprecipitated with anti-MYC magnetic beads. Immunoblots were developed with anti-BAK1 antibody to detect BAK1 and with anti-MYC to detect OsWDRP3 (Fig. 6C).

We used in vitro degradation experiments to investigate whether OsWDRP3 promotes the degradation of the OsBAK1 protein. Purified OsBAK1-6His was incubated with protein extracts from wild-type, OsWDRP3-RNAi, and OsWDRP3-OE plants and detected with anti- $6 \times$ His, anti-OsBAK1, and antiplant actin antibodies. As shown in Figure 7, when the purified OsBAK $1^{259-624}$ and OsBAK1 $1^{307-624}$ proteins were incubated with the wild-type protein extract, only OsBAK $1^{259-624}$ proteins were degraded, while OsBAK $1^{307-624}$ proteins were not degraded (Fig. 7A). Subsequently, we examined the effect of OsWDRP3 on the degradation of OsBAK $1^{259-624}$ protein. OsBAK $1^{259-624}$ protein was incubated with protein extracts from OsWDRP3-OE, wild-type and OsWDRP3-RNAi plants, and the degradation rate of OsBAK $1^{259-624}$ protein was slowed down in turn (Fig. 7B).

To verify the effect of OsWDRP3 on the degradation of OsBAK $1^{259-624}$ protein, we added purified OsWDRP3 into the protein extract of wild-type plants and then incubated OsBAK1 ${ }^{259-624}$ protein. The degradation rate of OsBAK $1^{259-624}$ protein in the reaction system with OsWDRP3 added was faster than that in the system without OsWDRP3 added (Fig. 7B and 7C).

\section{Discussion}

The WD provides a platform for protein interactions to form multiprotein complexes, which regulate important cellular pathways in eukaryotes (Smith et al. 1999; Bjerkan et al. 2012; Stirnimann et al. 2010; Cai et al. 2020; Kim et al. 2021; Choi et al. 2021; Jain and Pandey 2018).

In this paper, we found that OsWDRP3, as a WD40 protein in rice, is involved in the regulation of upright leaf growth. Based on the characterization of WD proteins, we analyzed the interacting proteins of OsWDRP3 to reveal the functions of OsWDRP3 in regulating leaf upright growth, and because OsWDRP3-RNAi transgenic plants showed BR insensitivity and semidwarfism, we chose those proteins that are related to BR signaling in rice.

Among these BR-related proteins, BRI1-associated kinase 1 (BAK1) was proven to interact with OsWDRP3. BAK1 is a Thr/Ser/Tyr kinase with five leucine-rich repeat (LRR) copies. As a coreceptor, BAK1 mediates multiple signaling pathways, including BR signaling and PAMP-triggered immunity (He et al. 2013). Fine-tuning of BAK1 is essential to its function. Several proteins are involved in the regulation of BAK1. For example, BAK1-interacting receptor-like kinases3 (BIR3) can interact with BAK1 to prevent BAK1 receptor complex formation, thus negatively regulating BR signaling (Imkampe et al. 2017). MSBP1 (a membrane steroid-binding protein 1) can bind to BAK1 in vitro and is negatively involved in BR signaling (Song et al. 2009). Overexpression of a truncated intracellular domain of OsBAK1 (without the extracellular domain) results in BR insensitivity and a dwarfed phenotype (Li et al. 2009). These results indicate that the increase in BAK1 content in the cytoplasm can inhibit BR signal transduction. 
Posttranslational regulation takes part in BR signaling. BES1 and BZR1 can be degraded by the proteasome (Wang et al. 2013; He et al. 2002). Whether BAK1 is regulated by protein degradation has not been reported. Through bioinformatics analysis, we identified the homologous genes of the OsWDRP3 gene in Arabidopsis as At1g15470/XIW1, At3g15610 and At1g52730 (Zhang et al. 2008). Among them, XIW1 is XP01-interacting WD40 protein 1 and interacts with ABA insensitive 5 (ABI5) in the nucleus and is involved in regulating the stability of $A B I 5$ (Xu et al. 2019; Cai et al. 2020). Our previous work in Arabidopsis thaliana showed that a WD protein is involved in the degradation of the protein kinase CRK5 (Teng et al. 2016). OsWDRP3 is a serine-threonine kinase receptor-associated protein. Based on our results, we speculated that OsWDRP3 might interact with the BR-related serine-threonine kinase BAK1 and be involved in the intracellular degradation of BAK1 (Fig. 8). OsBAK1-GFP fusion protein is principally located on the plasma membrane. However, OsBAK1-GFP is abundant in the cytoplasm during plasmolysis experiments and distributes in a spot-like way (Li et al. 2009). This result suggested that BAK1 might break off above the membrane and enter the cytoplasm under treatment conditions. After BAK1 departs from the membrane and enters the cytoplasm through endocytosis, BAK1 might be degraded mediated by WDRP3 in the cytoplasm. It has been reported that overexpressed BAK1K in the cytoplasm inhibits BR signal transduction, leading to a BR-insensitive and dwarfed phenotype (Li et al. 2009). BAK1K in the cytoplasm can also bind to BRI1, but unlike BAK1 localized to the cell membrane, BAK1K in the cytoplasm cannot act as a coreceptor in BR signal transduction. Therefore, excess BAK1K in the cytoplasm can inhibit BR signaling to some extent (Fig. 8). In our future research, we will further try to reveal how WDRP3 participates in degradation in the cytoplasm in rice.

In summary, we showed the involvement of OsWDRP3 in BR signaling in rice, and the findings implied that OsWDRP3 might be a potential genetic module for future rice breeding strategies.

\section{Methods}

\section{Plant materials and growth conditions}

The RNAi and OE lines were generated on the Hejiang 19 background. All rice plants were grown in paddy fields from May to September in Wuhan $\left(104.06^{\circ} \mathrm{E}, 30.67^{\circ} \mathrm{N}\right)$, China. In winter, the plants were grown in green house with $16 \mathrm{~h}$ light and $8 \mathrm{~h}$ dark.

Dry rice seeds were immersed in $\mathrm{NaClO}$ solution (2\% active chlorine) for $30 \mathrm{~min}$, and then sterilized distilled water was used to wash away the remaining $\mathrm{NaClO}$. The sterilized seeds were dried and then transferred to MS solid medium (SIGMA-ALDRICH). After grown for $7-10$ days at $28^{\circ} \mathrm{C}$ with $16 \mathrm{~h}$ light and $8 \mathrm{~h}$ dark, the seedlings were transplanted to soil.

\section{Sequence analysis}

The OsWDRP3-related sequences from Arabidopsis were identified using Protein BLAST (https://blast.ncbi.nlm.nih.gov/Blast.cgi). Protein sequences were aligned using Jotun Hein Method. 


\section{Vector construction and rice transformation}

To generate the RNAi construct (Ubi:RNAi-OsWDRP3), the region containing $539 \mathrm{bp}$ of the OsWDRP3 coding sequence was amplified from Hejiang $19 \mathrm{cDNA}$ and then transferred into the plant binary RNAi vector pUbi (modified from pCambia1301). The hairpin structure with two inverted repeat fragments was expressed under the control of the maize ubiquitin promoter.

To generate the over-express construct (Ubi::OsWDRP3), the full-coding region of OsWDRP3 was amplified from Hejiang 19 cDNA and inserted into pCambia1300-3×Flag.

The constructed transgenic vector was transferred into EHA105 (Agrobacterium tumefaciens strain). Sterilized wild-type rice seeds were planted on callus induction medium (N6 medium including vitamins, $0.06 \%$ casein hydrolysate, $3 \%$ sucrose, $2.5 \mathrm{mg} / \mathrm{L} \mathrm{2}$, 4-dichlorophenoxyacetic acid, pH 5.8). After 4 weeks, embryonic calli were used to co-cultivate with Agrobacterium containing the transgenic vector (Ubi::RNAiOsWDRP3 or Ubi::OsWDRP3). Transformed calli were selected on the $40 \mathrm{mg} / \mathrm{L}$ hygromycin-containing callus induction medium and transferred to the regeneration medium.

The expression of OsWDRP3 in the wild type, OsWDRP3-RNAi and OsWDRP3-OE plants were examined by qRT-PCR.

\section{RNA isolation and RT-PCR analyses}

Total RNA was isolated from seedlings using the plant RNA purification reagent (Invitrogen). Transcript levels were detected by qRT-PCR. DNase (Fermentas) -treated total RNA $(1 \mu \mathrm{g})$ were used to generate cDNA templates by Revert M-MuLV reverse transcriptase (Fermentas). qRT-PCR reactions were performed with denaturation $95^{\circ} \mathrm{C}$ for $5 \mathrm{~min}, 30$ cycles of $95^{\circ} \mathrm{C}$ for $10 \mathrm{~s}, 60^{\circ} \mathrm{C}$ for $60 \mathrm{~s}$ and $72^{\circ} \mathrm{C}$ for $60 \mathrm{~s}$. qRT-PCR was conducted using Biolab real-time PCR with SYBR Green Premix Ex Taqll

(Takara, https://www.takarabio.com) according to the manufacturer's instructions. Data were analyzed using CFX manager software (Bio-Rad; www.bio-rad.com). For each gene, three replicates were analyzed. Each analysis was biologically repeated twice. OsUBQ10 was used to normalize the qRT-PCR data.

\section{Histochemical GUS analysis}

To obtain pOsWDRP3::GUS transgenic plants, a 3630 bp promoter region of OsWDRP3 was amplified using the forward primer 5'- CCCAAGCTTGAAGACATGGCAATTTGGT-3' and the reverse primer 5'CCCAAGCTTTGCATCAATCTCAACCCC-3' from the genome of Hejiang19, and inserted into the Hind III site of the PCAMBIA-1381Xb-GUS vector.

Fresh samples from pOsWDRP3::GUS transgenic plants were incubated in a GUS staining solution at 37 ${ }^{\circ} \mathrm{C}$ for $24 \mathrm{~h}$. The GUS staining solution includes50 mM phosphate buffer ( $\left.\mathrm{pH} 7.2\right), 0.5 \%(\mathrm{v} / \mathrm{v})$ Triton-X100, $5 \mathrm{mM}$ potassium ferricyanide, $5 \mathrm{mM}$ potassium ferrocyanide and $2 \mathrm{mM}$ 5-bromo-4-chloro-3-indolyl- $\beta$-D 
glucuronide. Then the samples were treated with fresh $70 \%$ ethanol until no chlorophyll color left. In the end, we used microscope (DM1000; Leica, Wetzlar, Germany) to examine the samples and photographed with a digital camera.

\section{Rice Protoplast Transformation}

The wild-type rice seeds were placed on MS solid medium to grow for 8-10 days. The shoots of seedling were cut into 0.5 -mm strips, and then incubated in enzyme solution with gentle shaking (50 rpm) at $28{ }^{\circ} \mathrm{C}$ for $4-5 \mathrm{~h}$ in the dark. The enzyme solution includes $0.6 \mathrm{M}$ mannitol, $10 \mathrm{mM}$ MES, $1.5 \%$ cellulase RS, $0.75 \%$ macerozyme R-10, 1 mM CaCl $2,0.1 \%$ BSA, $5 \mathrm{mM} \beta$-mercaptoethanol, pH 5.7. $10 \mathrm{~mL}$ of pre-cooled W5 solution ( $154 \mathrm{mM} \mathrm{NaCl}, 125 \mathrm{mM} \mathrm{CaCl}_{2}, 5 \mathrm{mM} \mathrm{KCl}, 2 \mathrm{mM} \mathrm{MES}, \mathrm{pH}$ 5.7) was slowly added to the enzymatic hydrolysate. Then the solution was filtered through a $35 \mathrm{~mm}$ nylon mesh. The protoplasts were collected by centrifugation at $1500 \mathrm{r} / \mathrm{min}$ for $3 \mathrm{~min}$. The supernatant was sucked out with pipetting gun, then $2 \mathrm{~mL}$ of precooled MMG solution (0.6 M mannitol, $15 \mathrm{mM} \mathrm{MgCl} 2,4 \mathrm{mM} \mathrm{MES}, \mathrm{pH}$ 5.7) was gently added to the protoplast, and then added $8 \mathrm{~mL}$ precooled MMG solution was mixed and ice bathed for $30 \mathrm{~min}$ to restore the vitality of protoplasts. The solution was centrifuged at $1500 \mathrm{r} / \mathrm{min}$ for $3 \mathrm{~min}$, and then discarded the supernatant. The protoplasts were gently resuspended to a density of $2 \times 10^{6} / \mathrm{mL}$ with MMG solution. Next, plasmid was mix with $100 \mu \mathrm{L}$ of resuspended protoplasts, and then $110 \mu \mathrm{L}$ of polyethylene glycol (PEG) solution (0.6 M mannitol, $100 \mathrm{mM} \mathrm{CaCl}_{2}, 40 \%$ [w/v] PEG 3350) were added evenly. The mixture was incubated at $28^{\circ} \mathrm{C}$ for $20 \mathrm{~min}$. After centrifugation at $1500 \mathrm{r} / \mathrm{min}$ for $3 \mathrm{~min}$, the protoplasts were resuspended in W5 solution with proper volume, and then incubated overnight at $28^{\circ} \mathrm{C}$ in the dark.

\section{Subcellular localization of the OsWDRP3 protein}

To determine the subcellular localization of the OsWDRP3 protein, the full-length ORF of OsWDRP3 was cloned into the pmGFP4 vector, driven by the CaMV 35S promoter. The fusion construct was transferred into rice protoplasts, and the empty pmGFP4 as a control. This plasmid was introduced into the rice protoplasts through polyethylene glycol-mediated transformation (Wang et al., 2013; Lichocka and Schmelzer, 2014). The subcellular localizations of OsWDRP-mGFP were observed using a laser scanning confocal microscope at the proper time after transformation or infiltration (Leica DMI6000 equipped with a Leica TCS SP8 confocal laser-scanning device, Leica Microsystems).

\section{Brassinosteroid sensitivity assay}

For lamina joint inclination analysis, after sterilization, the seeds were cultured in MS solid medium at 28 ${ }^{\circ} \mathrm{C}$ until two-leaf stage. $1 \mu \mathrm{L}$ of ethanol solution containing various concentrations $(0,10,100,1000 \mathrm{ng} /$ $\mu \mathrm{L}$ ) of 24-epiBL were dropped at the lamina joints of the second leaf. After cultured for 2 days, the angles 
of the second leaf were photographed and measured with IMAGEJ. For each treatment, 10 plants were used to measure the angle. All the experiments were repeated three times

For coleoptile elongation analysis, seeds were germinated in MS solid medium with or without $1 \mu \mathrm{M} \mathrm{eBL}$ at $28^{\circ} \mathrm{C}$ in darkness for 3 days.

For root elongation analysis, seeds were soaked in water for 2 days at $28{ }^{\circ} \mathrm{C}$. Geminated rice seeds were then transferred to MS liquid medium with or without $1 \mu \mathrm{M}$ eBL at $28^{\circ} \mathrm{C}$ for 5 days.

\section{Immunoblots}

One-week-old seedlings were soaked in liquid nitrogen and then ground to extract protein. Immunoblots analysis were followed the same methods as described by Teng et al. (2016). Protein sample was separated by $10 \%$ SDS-PAGE, then transferred onto NC Membrane (Millipore). The membrane was incubated for $2 \mathrm{~h}$ in TBST blocking buffer (50 mM Tris- $\mathrm{HCl}, \mathrm{pH} 8.0,150 \mathrm{mM} \mathrm{NaCl}, 0.05 \%$ Tween 20, and $5 \%$ dry skimmed milk) with anti-BAK1 or anti-6x His antibody (1:1000 dilution). After washing with TBST three times, the membranes were incubated for $1 \mathrm{~h}$ with an anti-rabbit secondary antibody (Pierce; dilution 1:5000). After washing with TBST, horseradish peroxidase substrate (TIANGEN) was used for color rendering.

\section{Bimolecular Fluorescence Complementation (BIFC)}

To generate the BiFC constructs, the coding region of OsWDRP3 without stop codons was sub-cloned into $35 S-S P Y N E$ vector, and the coding region of OsBAK $1^{307-624}$ was sub-cloned into $35 S$-SPYNE vector.

For transient expression, Agrobacterium tumefaciens strains GV3101 carrying 35S-OsWDRP3-SPYNE and 35S-OsBAK ${ }^{307-624-S P Y C E}$ were infiltrated into 5-6-week-old Nicotiana benthamiana leaves (Waadt et al., 2014). BIFC for rice protoplast transformation was followed the method by Wang et al (2013). Microscopic techniques were performed refer to Offenborn et al. (2015). Images were processed using the Adobe Photoshop software package.

\section{In vivo co-immunoprecipitation (Co-IP) assay}

The rice seedlings leaves isolated from Ubi::OsWDRP3-Myc transgene plant were ground in protein extraction buffer ( $25 \mathrm{mM}$ Tris- $\mathrm{HCl}, \mathrm{pH} 7.5,150 \mathrm{mM} \mathrm{NaCl}, 5 \%$ glycerol, 1 mM EDTA, 1 mM PMSF, $1 \times$ complete cocktail of protease inhibitors (Roche), $1 \mathrm{mM} \mathrm{DTT}$ ). The extracts were centrifuged at 13,000 $g$ for $10 \mathrm{~min}$. The supernatant was used as a total protein for subsequent experiments. The protein concentration was determined using the Bio-Rad protein assay kit. $5 \mathrm{mg}$ of total proteins was mix with 30 $\mu \mathrm{l}$ of anti-MYC monoclonal antibodies (Bioss, Beijing, China) immobilized on Sepharose Fast Flow beads at $4{ }^{\circ} \mathrm{C}$ overnight. After washing with the protein extraction buffer, the precipitated samples were eluted by 
SDS protein loading buffer with boiling for $5 \mathrm{~min}$. The protein complex was analyzed by western blotting using the anti-myc monoclonal rabbit antibody (1:2000), anti-BAK1 (1:200) and anti-plant actin (1:2000, Abbkine) antibodies, respectively.

\section{In vitro Cell-free degradation assay}

For recombinant proteins used in the assay, cDNAs were recombined into pET28a vectors to obtain fusion proteins with $6 \times$ His tag. Recombinant proteins were expressed in Escherichia coli strain Rosetta (DE3) and purified using Ni-NTA resin (QIAGEN). The protein concentration was determined using the BioRad protein assay kit.

Cell-free degradation assays were carried out as previously described (Wang et al., 2009). Total protein was extracted from 7-day-old Hejiang19, OsWDRP3-RNAi or OsWDRP3-OE seedlings using extraction buffer ( $25 \mathrm{mM}$ Tris- $\mathrm{HCl}, \mathrm{pH} 7.5,10 \mathrm{mM} \mathrm{MgCl}_{2}, 5 \mathrm{mM}$ DTT, and protease inhibitor mixture). After centrifugation at $18,000 \times \mathrm{g}$ for $20 \mathrm{~min}$ at $4{ }^{\circ} \mathrm{C}$, the supernatant was transferred to a new tube.

For the degradation assay, $2.6 \mu \mathrm{g}$ of recombinant OsBAK $1^{259-624}$ or OsBAK ${ }^{1307-624}$ was incubated with $0.5 \mathrm{mg}$ of total protein extract, $10 \mathrm{mM} \mathrm{MgCl}_{2}$ and $10 \mathrm{mM}$ ATP. The final reaction volume was $400 \mu \mathrm{L} .30$ $\mu \mathrm{L}$ of the reaction mixture was taken out at $0,5,15,30,60$ and 120 min respectively and mix with $5 \times$ SDS loading buffer to stop the reaction. As control, $30 \mu \mathrm{M}$ MG132 as proteasome inhibitor was added before the start of the control assay. Protein levels were determined by immunoblots using $6 \times$ His antibodies (Roche) at 1:5,000 dilution followed by horseradish peroxidase- conjugated anti-mouse IgG (Sigma) at $1: 2,000$ dilution.

\section{Declarations}

\section{Author contributions}

Di Xi and Zi-Ying Wang designed the research, performed experiments, and analyzed data. Chen-Jie Long performed some of the experiments. Lei Zhang designed the research, wrote the paper, and supervised the project.

\section{Funding}

This work was supported by the National Natural Science Foundation of China (Grant No. 31570288).

\section{Availability of data and materials}

All data generated or analyzed in this study are included in this published article and its additional information files. 


\section{Ethics approval and consent to participate}

Not applicable.

\section{Consent for publication}

Not applicable.

\section{Competing interests}

The authors declare that they have no competing interests.

\section{Author details}

1State Key Laboratory of Hybrid rice, Wuhan University, Hubei 430072, China

2 Xinyang College, Henan 464000, China

*Correspondence: Lei Zhang (arabilab@whu.edu.cn)

\section{References}

1. Bai MY, Zhang LY, Gampala SS, Zhu SW, Song WY, Chong K, Wang ZY (2007) Functions of OsBZR1 and 14-3-3 proteins in brassinosteroid signaling in rice. Proc Natl Acad Sci U S A 104:13839-13844. doi: $10.1073 /$ pnas.0706386104.

2. Bashline L, Li S, Zhu X, Gu Y (2015) The TWD40-2 protein and the AP2 complex cooperate in the clathrin-mediated endocytosis of cellulose synthase to regulate cellulose biosynthesis. Proc Natl Acad Sci U S A 112: 12870-12875. doi: 10.1073/pnas.1509292112.

3. Beris D, Kapolas G, Livanos P, Roussis A, Milioni D, Haralampidis K (2016) RNAi-mediated silencing of the Arabidopsis thaliana ULCS1 gene, encoding a WDR protein, results in cell wall modification impairment and plant infertility. Plant Sci 245:71-83. doi: 10.1016/j.plantsci.2016.01.008.

4. Bjerkan KN, Jung-Roméo S, Jürgens G, Genschik P, Grini PE (2012) Arabidopsis WD repeat domain55 Interacts with DNA damaged binding protein 1 and is required for apical patterning in the embryo. Plant Cell 24: 1013-1033. doi: 10.1105/tpc.111.089425.

5. Bui M, Lim N, Sijacic P, Liu Z (2011) LEUNIG_HOMOLOG and LEUNIG regulate seed mucilage extrusion in Arabidopsis. J Integr Plant Biol 53:399-408. doi: 10.1111/j.1744-7909.2011.01036.x.

6. Cai J, Huang H, Xu X, Zhu G (2020) An Arabidopsis WD40 repeat-containing protein XIW1 promotes salt inhibition of seed germination. Plant Signal Behav 15:1712542.

doi:10.1080/15592324.2020.1712542. 
7. Cao H, Chen S (1995) Brassinosteroid-induced rice lamina joint inclination and its relation to indole3-acetic acid and ethylene. Plant Growth Regul 16:189-196. doi:10.1007/BF00029540.

8. Chen L, Xiong G, Cui X, Yan M, Xu T, Qian Q, Xue Y, Li J, Wang Y (2013) OsGRAS19 may be a novel component involved in the brassinosteroid signaling pathway in rice. Mol Plant 6:988-991. doi: $10.1093 / \mathrm{mp} / \mathrm{sst027.}$

9. Choi J, Lee W, An G, Kim SR (2021) OsCBE1, a substrate receptor of Cullin4-based E3 ubiquitin ligase, functions as a regulator of abiotic stress response and productivity in rice. Int J Mol Sci 22:2487. doi: $10.3390 /$ ijms22052487.

10. Duan K, Li L, Hu P, Xu SP, Xu ZH, Xue HW (2006) A brassinolide-suppressed rice MADS-box transcription factor, OsMDP1, has a negative regulatory role in BR signaling. Plant $J$ 47:519-531. doi: 10.1111/j.1365-313X.2006.02804.x.

11. Feng R, Zhang C, Ma R, Cai Z, Lin Y, Yu M (2019) Identification and characterization of WD40 superfamily genes in peach. Gene 710:291-306. doi: 10.1016/j.gene.2019.06.010.

12. Feng Z, Wu C, Wang C, Roh J, Zhang L, Chen J, Zhang S, Zhang H, Yang C, Hu J, You X, Liu X, Yang X, Guo X, Zhang X, Wu F, Terzaghi W, Kim SK, Jiang L, Wan J (2016) SLG controls grain size and leaf angle by modulating brassinosteroid homeostasis in rice. J Exp Bot 67:4241-4253. doi: 10.1093/jxb/erw204.

13. Guo J, Li W, Shang L, Wang Y, Yan P, Bai Y, Da X, Wang K, Guo Q, Jiang R, Mao C, Mo X (2021) OsbHLH98 regulates leaf angle in rice through transcriptional repression of OsBUL1. New Phytol 230:1953-1966. doi: 10.1111/nph.17303.

14. He JX, Gendron JM, Yang Y, Li J, Wang ZY (2002) The GSK3-like kinase BIN2 phosphorylates and destabilizes BZR1, a positive regulator of the brassinosteroid signaling pathway in Arabidopsis. Proc Natl Acad Sci U S A 99:10185-10190. doi: 10.1073/pnas.152342599.

15. He K, Xu S, Li J (2013) BAK1 directly regulates brassinosteroid perception and BRI1 activation. J Integr Plant Biol 55:1264-1270. doi: 10.1111/jipb.12122.

16. Hirano K, Yoshida H, Aya K, Kawamura M, Hayashi M, Hobo T, Sato-Izawa K, Kitano H, UeguchiTanaka M, Matsuoka M (2017) SMALL ORGAN SIZE 1 and SMALL ORGAN SIZE 2/DWARF AND LOW-TILLERING form a complex to integrate auxin and brassinosteroid signaling in rice. Mol Plant 10:590-604. doi: 10.1016/j.molp.2016.12.013.

17. Hong Z, Ueguchi-Tanaka M, Fujioka S, Takatsuto S, Yoshida S, Hasegawa Y, Ashikari M, Kitano H, Matsuoka M (2005) The Rice brassinosteroid-deficient dwarf2 mutant, defective in the rice homolog of Arabidopsis DIMINUTO/DWARF1, is rescued by the endogenously accumulated alternative bioactive brassinosteroid, dolichosterone. Plant Cell 17:2243-2254. doi: 10.1105/tpc.105.030973.

18. Hong Z, Ueguchi-Tanaka M, Shimizu-Sato S, Inukai Y, Fujioka S, Shimada Y, Takatsuto S, Agetsuma M, Yoshida S, Watanabe Y, Uozu S, Kitano H, Ashikari M, Matsuoka M (2002) Loss-of-function of a rice brassinosteroid biosynthetic enzyme, $\mathrm{C}-6$ oxidase, prevents the organized arrangement and polar elongation of cells in the leaves and stem. Plant J 32:495-508. doi: 10.1046/j.1365313x.2002.01438.x. 
19. Hong Z, Ueguchi-Tanaka M, Umemura K, Uozu S, Fujioka S, Takatsuto S, Yoshida S, Ashikari M, Kitano H, Matsuoka M (2003) A rice brassinosteroid-deficient mutant, ebisu dwarf (d2), is caused by a loss of function of a new member of cytochrome P450. Plant Cell 15:2900-2910. doi: $10.1105 /$ tpc. 014712 .

20. Hu R, Xiao J, Gu T, Yu X, Zhang Y, Chang J, Yang G, He G (2018) Genome-wide identification and analysis of WD40 proteins in wheat (Triticum aestivum L.). BMC Genomics 19:803. doi: 10.1186/s12864-018-5157-0.

21. Hu X, Qian Q, Xu T, Zhang Y, Dong G, Gao T, Xie Q, Xue Y (2013) The U-box E3 ubiquitin ligase TUD1 functions with a heterotrimeric $\mathrm{G}$ a subunit to regulate Brassinosteroid-mediated growth in rice. PLoS Genet 9:e1003391. doi: 10.1371/journal.pgen.1003391.

22. Imkampe J, Halter T, Huang S, Schulze S, Mazzotta S, Schmidt N, Manstretta R, Postel S, Wierzba M, Yang Y, van Dongen WMAM, Stahl M, Zipfel C, Goshe MB, Clouse S, de Vries SC, Tax F, Wang X, Kemmerling B (2017) The Arabidopsis Leucine-Rich repeat receptor kinase BIR3 negatively regulates BAK1 receptor complex formation and stabilizes BAK1. Plant Cell 29:2285-2303. doi: 10.1105/tpc.17.00376.

23. Ito $Y$, Thirumurugan T, Serizawa A, Hiratsu K, Ohme-Takagi M, Kurata N (2011) Aberrant vegetative and reproductive development by overexpression and lethality by silencing of OsHAP3E in rice. Plant Sci 181:105-110. doi:10.1016/j.plantsci.2011.04.009.

24. Jain BP, Pandey S (2018) WD40 repeat proteins: signalling scaffold with diverse functions. Protein J 37:391-406. doi: 10.1007/s10930-018-9785-7.

25. Jang S, An G, Li HY (2017) Rice leaf angle and grain size are affected by the OsBUL1 transcriptional activator complex. Plant Physiol 173:688-702. doi: 10.1104/pp.16.01653.

26. Jeon JS, Lee S, Jung KH, Jun SH, Jeong DH, Lee J, Kim C, Jang S, Yang K, Nam J, An K, Han MJ, Sung RJ, Choi HS, Yu JH, Choi JH, Cho SY, Cha SS, Kim SI, An G (2000) T-DNA insertional mutagenesis for functional genomics in rice. Plant J 22:561-570. doi: 10.1046/j.1365313x.2000.00767.x.

27. Jeong DH, An S, Park S, Kang HG, Park GG, Kim SR, Sim J, Kim YO, Kim MK, Kim SR, Kim J, Shin M, Jung $M$, An $G$ (2006) Generation of a flanking sequence-tag database for activation-tagging lines in japonica rice. Plant J 45:123-132. doi: 10.1111/j.1365-313X.2005.02610.x.

28. Jiang Y, Bao L, Jeong SY, Kim SK, Xu C, Li X, Zhang Q (2012) XIAO is involved in the control of organ size by contributing to the regulation of signaling and homeostasis of brassinosteroids and cell cycling in rice. Plant J 70:398-408. doi: 10.1111/j.1365-313X.2011.04877.x.

29. Kim B, Jeong YJ, Corvalán C, Fujioka S, Cho S, Park T, Choe S (2014) Darkness and gulliver2/phyB mutation decrease the abundance of phosphorylated BZR1 to activate brassinosteroid signaling in Arabidopsis. Plant J 77:737-747. doi: 10.1111/tpj.12423.

30. Kim YJ, Kim MH, Hong WJ, Moon S, Kim EJ, Silva J, Lee J, Lee S, Kim ST, Park SK, Jung KH (2021) GORI, encoding the WD40 domain protein, is required for pollen tube germination and elongation in rice. Plant J 105:1645-1664. doi: 10.1111/tpj.15139. 
31. Lee JH, Terzaghi W, Gusmaroli G, Charron JB, Yoon HJ, Chen H, He YJ, Xiong Y, Deng XW (2008). Characterization of Arabidopsis and rice DWD proteins and their roles as substrate receptors for CUL4-RING E3 ubiquitin ligases. Plant Cell 20:152-167. doi: 10.1105/tpc.107.055418.

32. Lee S, Choi SC, An G (2008) Rice SVP-group MADS-box proteins, OsMADS22 and OsMADS55, are negative regulators of brassinosteroid responses. Plant J 54:93-105. doi: 10.1111/j.1365313X.2008.03406.x.

33. Li D, Wang L, Wang M, Xu YY, Luo W, Liu YJ, Xu ZH, Li J, Chong K (2009) Engineering OsBAK1 gene as a molecular tool to improve rice architecture for high yield. Plant Biotechnol J 7:791-806. doi: 10.1111/j.1467-7652.2009.00444.x.

34. Li H, He Z, Lu G, Lee SC, Alonso J, Ecker JR, Luan S (2007) A WD40 domain cyclophilin interacts with histone $\mathrm{H} 3$ and functions in gene repression and organogenesis in Arabidopsis. Plant Cell 19:24032416. doi: 10.1105/tpc.107.053579.

35. Li X, Wu P, Lu Y, Guo S, Zhong Z, Shen R, Xie Q (2020) Synergistic interaction of phytohormones in determining leaf angle in crops. Int J Mol Sci 21:5052. doi: 10.3390/ijms21145052.

36. Lichocka M, Schmelzer E (2014) Subcellular Localization Experiments and FRET-FLIM Measurements in Plants. Bio-protocol 4:e1018. doi: 10.21769/BioProtoc.1018.

37. Lin Z, Yan J, Su J, Liu H, Hu C, Li G, Wang F, Lin Y (2019) Novel OsGRAS19 mutant, D26, positively regulates grain shape in rice (Oryza sativa). Funct Plant Biol 46:857-868. doi: 10.1071/FP18266.

38. Mehdi S, Derkacheva M, Ramström M, Kralemann L, Bergquist J, Hennig L (2016) The WD40 domain protein MSI1 functions in a histone deacetylase complex to fine-tune abscisic acid signaling. Plant Cell 28:42-54. doi: 10.1105/tpc.15.00763.

39. Migliori V, Mapelli M, Guccione E (2012) On WD40 proteins: propelling our knowledge of transcriptional control? Epigenetics 7:815-822. doi: 10.4161/epi.21140.

40. Mishra AK, Muthamilarasan M, Khan Y, Parida SK, Prasad M (2014) Genome-wide investigation and expression analyses of WD40 protein family in the model plant foxtail millet (Setaria italica L.). PLoS One 9:e86852. doi: 10.1371/journal.pone.0086852.

41. Offenborn JN, Waadt R, Kudla J (2015) Visualization and translocation of ternary Calcineurin$\mathrm{A} /$ Calcineurin-B/Calmodulin-2 protein complexes by dual-color trimolecular fluorescence complementation. New Phytol 208:269-279. doi: 10.1111/nph.13439.

42. Ouyang Y, Huang X, Lu Z, Yao J (2012) Genomic survey, expression profile and co-expression network analysis of OsWD40 family in rice. BMC Genomics 13:100. doi: 10.1186/1471-2164-13-100.

43. Qiao S, Sun S, Wang L, Wu Z, Li C, Li X, Wang T, Leng L, Tian W, Lu T, Wang X (2017) The RLA1/SMOS1 transcription factor functions with OsBZR1 to regulate brassinosteroid signaling and rice architecture. Plant Cell 29:292-309. doi: 10.1105/tpc.16.00611.

44. Ruan W, Guo M, Xu L, Wang X, Zhao H, Wang J, Yi K (2018) An SPX-RLI1 module regulates leaf inclination in response to phosphate availability in rice. Plant Cell 30:853-870. doi:

10.1105/tpc.17.00738. 
45. Sakamoto T, Morinaka Y, Ohnishi T, Sunohara H, Fujioka S, Ueguchi-Tanaka M, Mizutani M, Sakata K, Takatsuto S, Yoshida S, Tanaka H, Kitano H, Matsuoka M (2006) Erect leaves caused by brassinosteroid deficiency increase biomass production and grain yield in rice. Nat Biotechnol 24:105-109. doi: 10.1038/nbt1173.

46. Salih H, Gong W, Mkulama M, Du X (2018) Genome-wide characterization, identification, and expression analysis of the WD40 protein family in cotton. Genome 61:539-547. doi: $10.1139 / \mathrm{gen}-$ 2017-0237.

47. Seo H, Kim SH, Lee BD, Lim JH, Lee SJ, An G, Paek NC (2020) The rice Basic Helix-Loop-Helix 79 (OsbHLHO79) determines leaf angle and grain shape. Int J Mol Sci 21:2090. doi: 10.3390/ijms21062090.

48. Sinclair TR, Sheehy JE (1999) Erect leaves and photosynthesis in rice. Science 283:1456-1457. doi: 10.1126/science.283.5407.1455c.

49. Smith TF, Gaitatzes C, Saxena K, Neer EJ (1999) The WD repeat: a common architecture for diverse functions. Trends Biochem Sci 24:181-185. doi: 10.1016/s0968-0004(99)01384-5.

50. Song L, Shi QM, Yang XH, Xu ZH, Xue HW (2009) Membrane steroid-binding protein 1 (MSBP1) negatively regulates brassinosteroid signaling by enhancing the endocytosis of BAK1. Cell Res 19:864-876. doi: 10.1038/cr.2009.66.

51. Stirnimann CU, Petsalaki E, Russell RB, Müller CW (2010) WD40 proteins propel cellular networks. Trends Biochem Sci 35:565-574. doi: 10.1016/j.tibs.2010.04.003.

52. Sui P, Jin J, Ye S, Mu C, Gao J, Feng H, Shen WH, Yu Y, Dong A (2012) H3K36 methylation is critical for brassinosteroid-regulated plant growth and development in rice. Plant $\mathrm{J}$ 70:340-347. doi: 10.1111/j.1365-313X.2011.04873.x.

53. Takeda K (1974) Studies on the character expression and inheritance of $d m$-type internode distribution pattern in dwarf rice plants. Bulletin of the Faculty of Fisheries Hokkaido University 22:19-30.

54. Tanabe S, Ashikari M, Fujioka S, Takatsuto S, Yoshida S, Yano M, Yoshimura A, Kitano H, Matsuoka M, Fujisawa Y, Kato H, Iwasaki Y (2005) A novel cytochrome P450 is implicated in brassinosteroid biosynthesis via the characterization of a rice dwarf mutant, $d$ warf 11 , with reduced seed length. Plant Cell 17:776-790. doi: 10.1105/tpc.104.024950.

55. Tanaka A, Nakagawa H, Tomita C, Shimatani Z, Ohtake M, Nomura T, Jiang C J, Dubouzet JG, Kikuchi S, Sekimoto H, Yokota T, Asami T, Kamakura T, Mori M (2009) BRASSINOSTEROID UPREGULATED1, encoding a helix-loop-helix protein, is a novel gene involved in brassinosteroid signaling and controls bending of the lamina joint in rice. Plant Physiol 151:669-680. doi: 10.1104/pp.109.140806.

56. Teng H-J, Guo Y, Wang J-Q, Li R, Lu Y-T, Zhang L (2016) WDRP, a DWD protein component of CUL4based E3 ligases, acts as a receptor of CDPK-related protein kinase 5 to mediate kinase degradation in Arabidopsis. J. Plant Biol 59:627-638. doi: 10.1007/s12374-016-0419-3. 
57. Tian X, He M, Mei E, Zhang B, Tang J, Xu M, Liu J, Li X, Wang Z, Tang W, Guan Q, Bu Q (2021) WRKY53 integrates classic brassinosteroid signaling and the mitogen-activated protein kinase pathway to regulate rice architecture and seed size. Plant Cell 18:koab137. doi: 10.1093/plcell/koab137.

58. Tong H, Jin Y, Liu W, Li F, Fang J, Yin Y, Qian Q, Zhu L, Chu C (2009) DWARF AND LOW-TILLERING, a new member of the GRAS family, plays positive roles in brassinosteroid signaling in rice. Plant $J$ 58:803-816. doi: 10.1111/j.1365-313X.2009.03825.x.

59. Tong H, Liu L, Jin Y, Du L, Yin Y, Qian Q, Zhu L, Chu C (2012) DWARF AND LOW-TILLERING acts as a direct downstream target of a GSK3/SHAGGY-like kinase to mediate brassinosteroid responses in rice. Plant Cell 24:2562-2577. doi: 10.1105/tpc.112.097394.

60. van Nocker S, Ludwig P (2003) The WD-repeat protein superfamily in Arabidopsis: conservation and divergence in structure and function. BMC Genomics 4:50. doi: 10.1186/1471-2164-4-50.

61. Waadt R, Schlücking K, Schroeder JI, Kudla J (2014) Protein fragment bimolecular fluorescence complementation analyses for the in vivo study of protein-protein interactions and cellular protein complex localizations. Methods Mol Biol 1062:629-658. doi: 10.1007/978-1-62703-580-4_33.

62. Wang F, Zhu D, Huang X, Li S, Gong Y, Yao Q, Fu X, Fan LM, Deng XW (2009) Biochemical insights on degradation of Arabidopsis DELLA proteins gained from a cell-free assay system. Plant Cell 21:23782390. doi: 10.1105/tpc.108.065433.

63. Wang K, Li MQ, Chang YP, Zhang B, Zhao QZ, Zhao WL (2020) The basic helix-loop-helix transcription factor OsBLR1 regulates leaf angle in rice via brassinosteroid signalling. Plant Mol Biol 102:589-602. doi: 10.1007/s11103-020-00965-5.

64. Wang K, Liu Y, Li S (2013) Bimolecular fluorescence complementation (BIFC) protocol for rice protoplast transformation. Bio Protoc 3:e979. doi: 10.21769/BioProtoc.979.

65. Wang L, Xu YY, Ma QB, Li D, Xu ZH, Chong K (2006) Heterotrimeric G protein alpha subunit is involved in rice brassinosteroid response. Cell Res 16:916-922. doi: 10.1038/sj.cr.7310111.

66. Wang L, Xu Y, Zhang C, Ma Q, Joo SH, Kim SK, Xu Z, Chong K (2008) OsLIC, a novel CCCH-Type zinc finger protein with transcription activation, mediates rice architecture via brassinosteroids signaling. PLoS One 3:e3521. doi: 10.1371/journal.pone.0003521.

67. Wang Y, Sun S, Zhu W, Jia K, Yang H, Wang X (2013) Strigolactone/MAX2-induced degradation of brassinosteroid transcriptional effector BES1 regulates shoot branching. Dev Cell 27:681-688. doi: 10.1016/j.devcel.2013.11.010.

68. Xiao Y, Zhang G, Liu D, Niu M, Tong H, Chu C (2020) GSK2 stabilizes OFP3 to suppress brassinosteroid responses in rice. Plant J 102:1187-1201. doi: 10.1111/tpj.14692.

69. Xu J, Wang JJ, Xue HW, Zhang GH (2021) Leaf direction: Lamina joint development and environmental responses. Plant Cell Environ 17:1-14. doi: 10.1111/pce.14065.

70. Xu X, Wan W, Jiang G, Xi Y, Huang H, Cai J, Chang Y, Duan CG, Mangrauthia SK, Peng X, Zhu JK, Zhu $\mathrm{G}$ (2019) Nucleocytoplasmic trafficking of the Arabidopsis WD40 repeat protein XIW1 regulates ABI5 stability and abscisic acid responses. Mol Plant 12:1598-1611. doi: 10.1016/j.molp.2019.07.001. 
71. Yamamuro C, Ihara Y, Wu X, Noguchi T, Fujioka S, Takatsuto S, Ashikari M, Kitano H, Matsuoka M (2000) Loss of function of a rice brassinosteroid insensitive1 homolog prevents internode elongation and bending of the lamina joint. Plant Cell 12:1591-606. doi: 10.1105/tpc.12.9.1591.

72. Zeng CJ, Lee YR, Liu B (2009) The WD40 repeat protein NEDD1 functions in microtubule organization during cell division in Arabidopsis thaliana. Plant Cell 21:1129-1140. doi: 10.1105/tpc.109.065953.

73. Zhang LY, Bai MY, Wu J, Zhu JY, Wang H, Zhang Z, Wang W, Sun Y, Zhao J, Sun X, Yang H, Xu Y, Kim SH, Fujioka S, Lin WH, Chong K, Lu T, Wang ZY (2009) Antagonistic HLH/bHLH transcription factors mediate brassinosteroid regulation of cell elongation and plant development in rice and Arabidopsis. Plant Cell 21:3767-3780. doi: 10.1105/tpc.109.070441.

74. Zhang Y, Feng S, Chen F, Chen H, Wang J, McCall C, Xiong Y, Deng XW (2008) Arabidopsis DDB1CUL4 ASSOCIATED FACTOR1 forms a nuclear E3 ubiquitin ligase with DDB1 and CUL4 that is involved in multiple plant developmental processes. Plant Cell 20:1437-1455. doi: 10.1105/tpc.108.058891.

75. Zhao J, Wu C, Yuan S, Yin L, Sun W, Zhao Q, Zhao B, Li X (2013) Kinase activity of OsBRI1 is essential for brassinosteroids to regulate rice growth and development. Plant Sci 199-200:113-120. doi: 10.1016/j.plantsci.2012.10.011.

76. Zhao M, Morohashi K, Hatlestad G, Grotewold E, Lloyd A (2008) The TTG1-bHLH-MYB complex controls trichome cell fate and patterning through direct targeting of regulatory loci.

Development 135:1991-1999. doi: 10.1242/dev.016873.

77. Zhao SQ, Hu J, Guo LB, Qian Q, Xue HW (2010) Rice leaf inclination2, a VIN3-like protein, regulates leaf angle through modulating cell division of the collar. Cell Res 20:935-947. doi: 10.1038/cr.2010.109.

78. Zhong R, Burk DH, Morrison WH 3rd, Ye ZH (2004) FRAGILE FIBER3, an Arabidopsis gene encoding a type II inositol polyphosphate 5-phosphatase, is required for secondary wall synthesis and actin organization in fiber cells. Plant Cell 16:3242-3259. doi: 10.1105/tpc.104.027466.

79. Zhou LJ, Xiao LT, Xue HW (2017) Dynamic cytology and transcriptional regulation of rice lamina joint development. Plant Physiol 174:1728-1746. doi: 10.1104/pp.17.00413.

80. Zhu J, Jeong JC, Zhu Y, Sokolchik I, Miyazaki S, Zhu JK, Hasegawa PM, Bohnert HJ, Shi H, Yun DJ, Bressan RA (2008) Involvement of Arabidopsis HOS15 in histone deacetylation and cold tolerance. Proc Natl Acad Sci U S A 105:4945-4950. doi: 10.1073/pnas.0801029105.

81. Zou XD, Hu XJ, Ma J, Li T, Ye ZQ, Wu YD (2016) Genome-wide Analysis of WD40 Protein Family in Human. Sci Rep 6:39262. doi: 10.1038/srep39262.

\section{Figures}




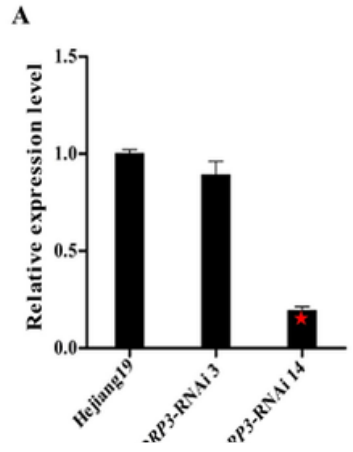

B
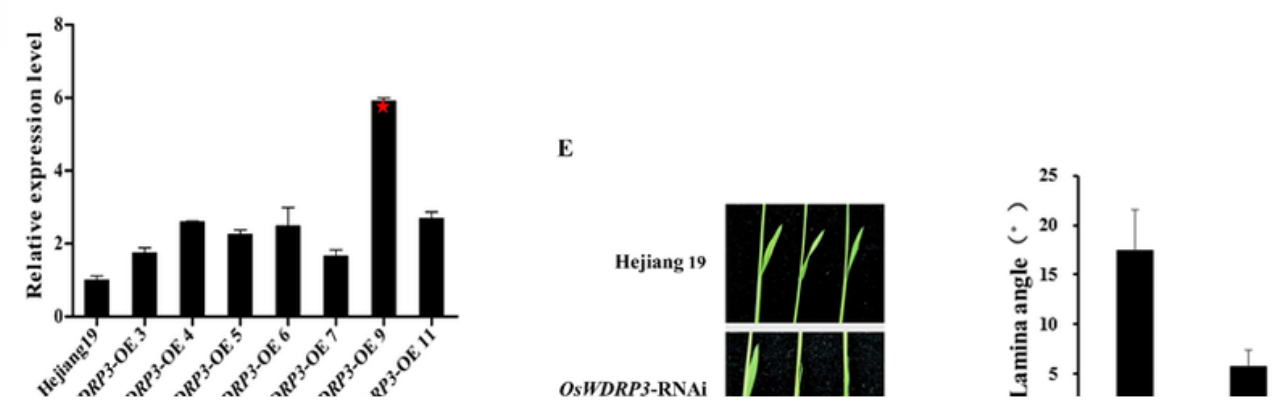

\section{Figure 1}

Phenotypic analysis of the RNAi (OsWDRP3-RNAi) and overexpression (OsWDRP3-OE) transgenic lines in the Hejiang 19 background.
A. Transcript abundance of OsWDRP3 in the leaves of Hejiang19 and OsWDRP3-RNAi plants as detected by qPCR.

B. Transcript abundance of OsWDRP3 in the leaves of Hejiang19 and OsWDRP3-OE plants as detected by qPCR.

C. Plant height of Hejiang19, OsWDRP3-RNAi and OsWDRP3-OE plants.

D. Internodes length of Hejiang19, OsWDRP3-RNAi and OsWDRP3-OE plants.

E. The OsWDRP3-RNAi plants displayed a smaller leaf inclination in seedlings.

F. The OsWDRP3-RNAi plant displays a smaller leaf inclination than that in Hejiang 19. Flag leaf: the first fully expanded leaf from the top of the main stems; $2^{\text {nd. }}$ : the second fully expanded leaf from the top of the main stems; $3^{\text {rd }}$ : the third fully expanded leaf from the top of the main stems. Values represent means $\pm S D$ of 10 replicates. $(* \star P<0.01)$. 
A

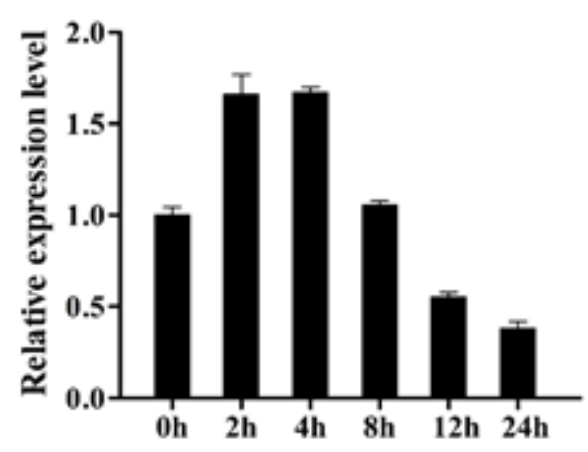

B
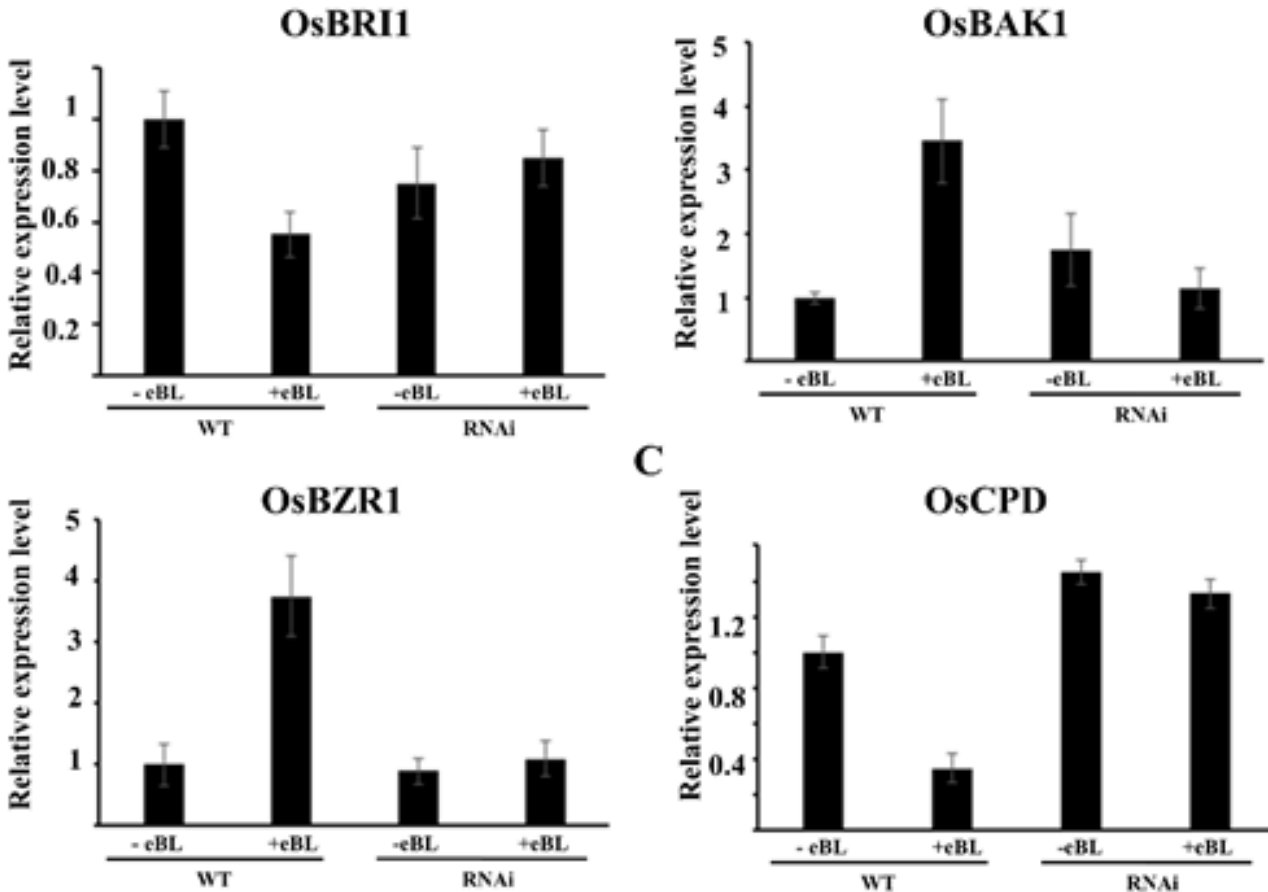

C

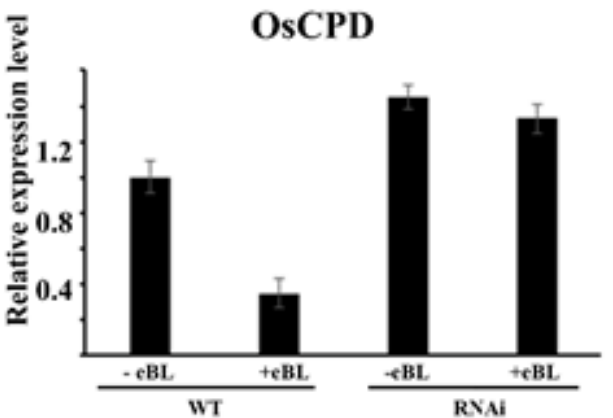

D2

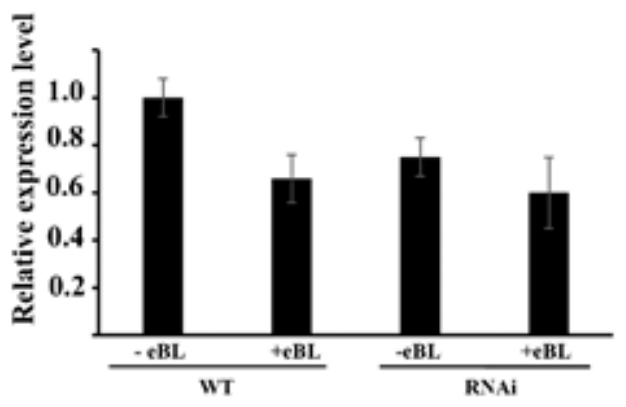

D11

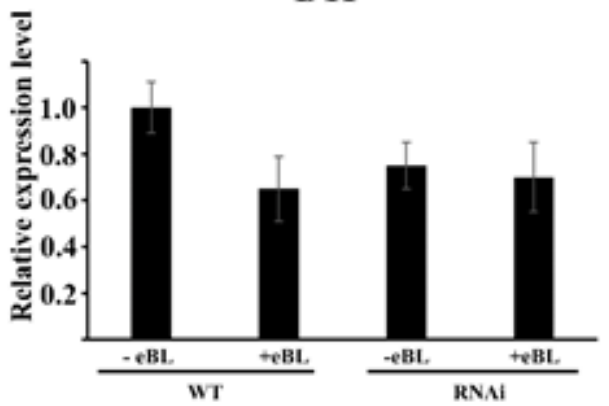

Figure 2

\section{Responses to BR Treatment in OsWDRP4-Modified Plants}

A. The expression of OsWDRP3 gene under BR treatment. Wild-type rice seedlings were treated with $1 \mu \mathrm{M}$ eBL, total RNA was extracted at 0 h, 2 h, 4 h, 8 h, 12 h and 24 h, and cDNA was synthesized by reverse transcription in vitro. 
B. Transcript levels of BR-responsive genes in Hejiang19 and OsWDRP3-RNAi plants.

C. Transcript levels of BR biosynthesis gene genes in Hejiang19 and OsWDRP3-RNAi plants under BR treatment.

In $\mathrm{B}$ and $\mathrm{C}$, total RNA was extracted from seedlings with $1 \mu \mathrm{M}$ eBL treatment for $6 \mathrm{~h}$, and $\mathrm{CDNA}$ was synthesized by reverse transcription in vitro. The relative abundance of transcripts was estimated as the relative fold change of transcripts in a sample compared to those at Hejiang 19 without BR treatment.

A
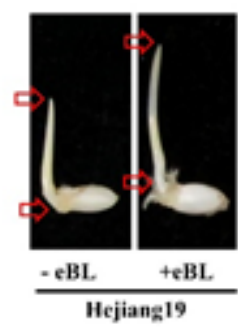

B
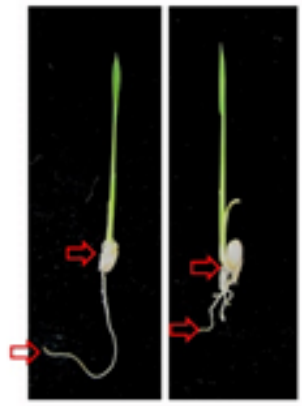

$\frac{-\mathrm{eBL} \quad+\mathrm{eBL}}{\text { Hejiang } 19}$

C

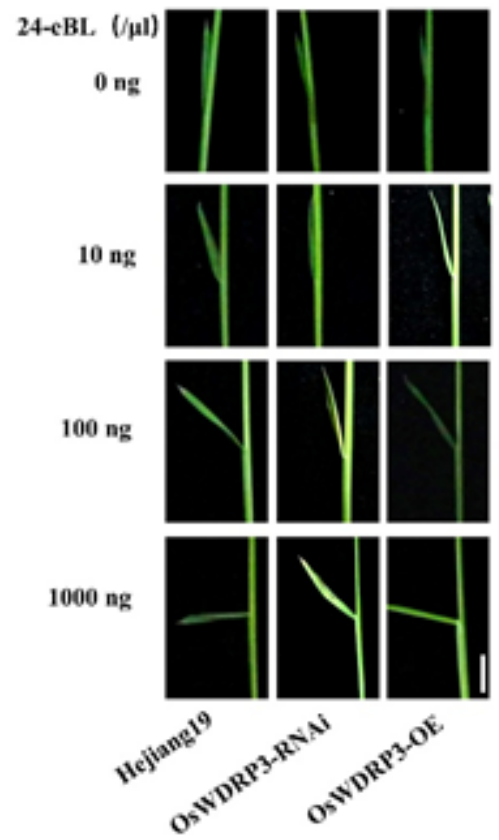

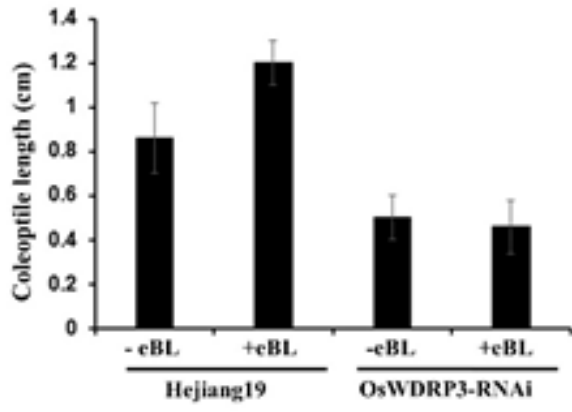
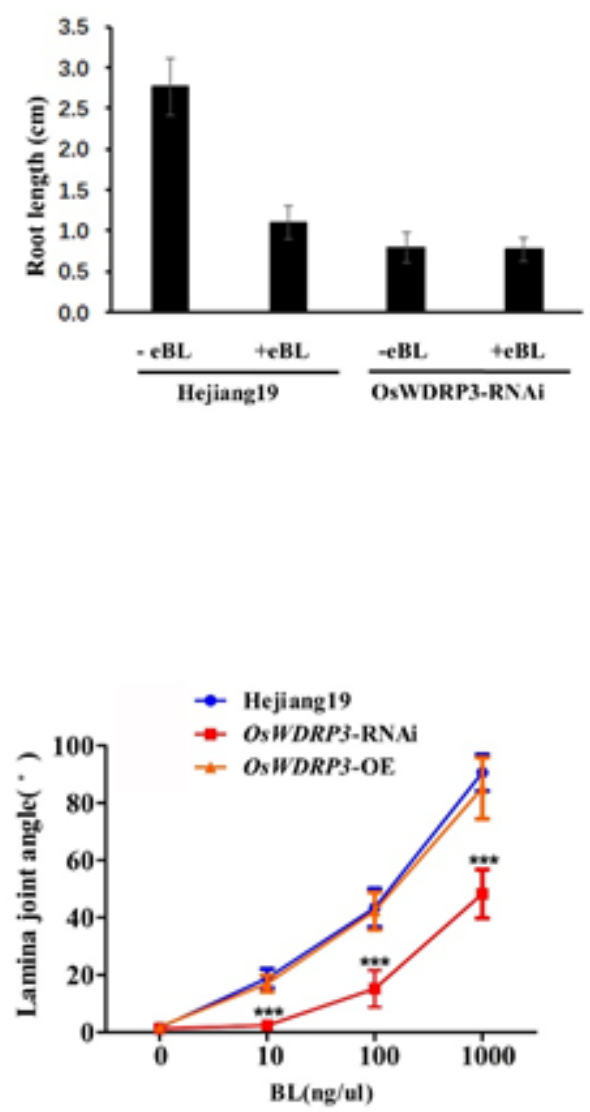


\section{Figure 3}

\section{OsWDRP3-RNAi plants showed a brassinosteroid-insensitive phenotype}

A. Effect of $1 \mu \mathrm{M}$ eBL on coleoptile elongation in Hejiang19 and OsWDRP3-RNAi seedlings.

B. Root growth inhibition in response to $1 \mu \mathrm{M}$ eBL $\mathrm{n}$ in Hejiang19 and OsWDRP3-RNAi seedlings. Data presented in $A$ and $B$ are the means from 10 plants. Error bars indicate SE.

C. Lamina joint inclination assay. Quantification of lamina joint angle in right. Error bars indicate SE ( $\mathrm{n}=$ 10). Significant differences at $p<0.01$ by ANOVA.

\section{Figure 4}

\section{Sequence and structure analysis of OsWDRP3}

A. Protein structure of OsWDRP3 depicting the predicted WD40 region. The WD40 domains were predicted using the SMART motif search program (http://smart.embl-heidelberg.de/).

B. Amino acid sequence alignment of OsWDRP3 with WD40 proteins in Arabidopsis. Alignment was carried out using clustalW. Amino acid residues conserved among all the proteins listed are shaded. 
A

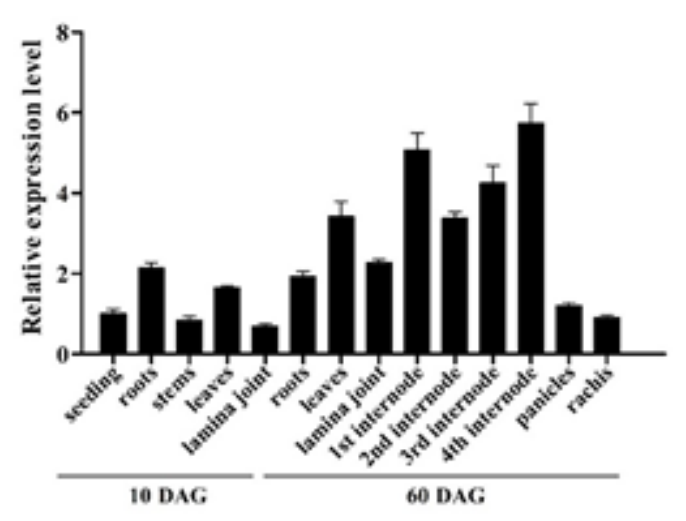

B

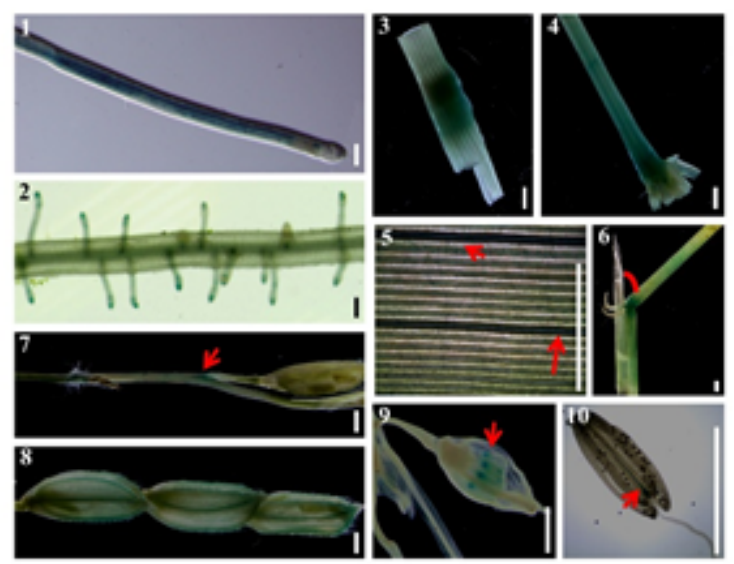

C
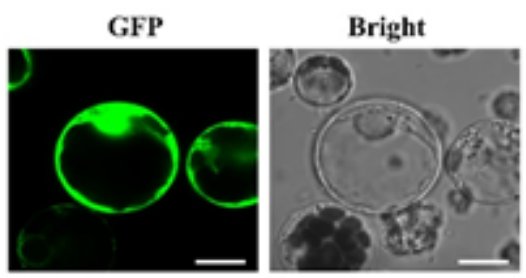

Merged

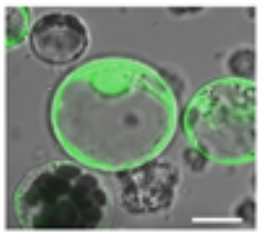

GFP
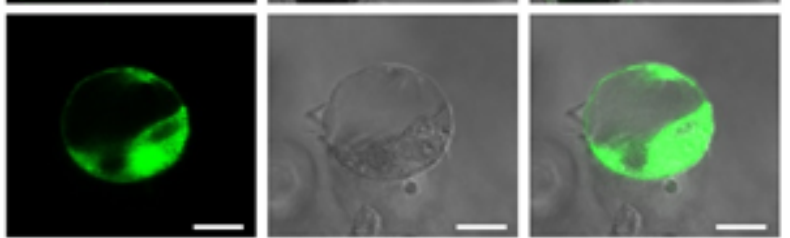

OsWDRP3-GFP

\section{Figure 5}

\section{Expression pattern of OsWDRP3.}

A. Relative abundance of OsWDRP3 in different tissues by qPCR. The relative abundance of transcripts was estimated as the relative fold change of transcripts in a sample compared to those at the seedling stage. The expression level of the rice $\beta$-Actin gene was determined as a control. Values are the means \pm SDs of at least three independent experiments.

B. Histochemical GUS staining of rice plants harboring OsWDRP3::GUS. 1: Root. 2: Lateral root. 3:

Internode. 4: Stem. 5: Leaves, arrows indicate GUS staining of the vascular bundle. 6: The leaf lamina joint. 7: Rachilla and spikelet. 8: Palea and lemma. Stained blue line is a vascular bundle. 9: Flower. The red arrow showed anther. 10: Mature anther.

C.Subcellular localization of the OsWDRP3 protein. Localizations of 35S::GFP and 35S::WDRP3-GFP in rice protoplast cells are shown. Bars $=20 \mu \mathrm{m}$. 
A

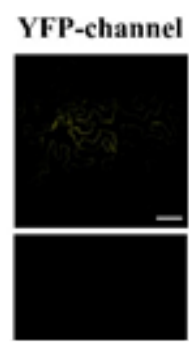

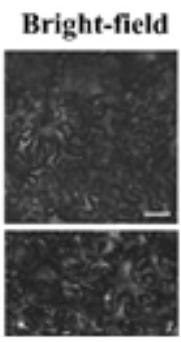

Merged

B
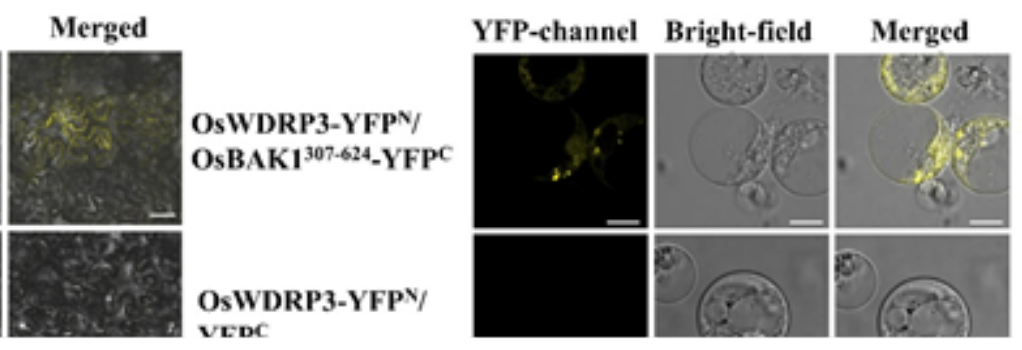

\section{Figure 6}

\section{OsWDRP3 Interacts with OsBAK1 by Binding to Its Kinase Domain}

A. Bimolecular fluorescence complementation (BiFC) analysis of the interactions between OsWDRP3 and OsBAK $1^{307-624}$ in tobacco leaf epidermal cells.

B. BiFC analysis of the interactions between OsWDRP3 and OsBAK $1^{307-624}$ in rice protoplasts.

C. The interaction between OsWDRP3 and OsBAK1 was detected by Co-IP. Input, extracted proteins; IP, immunoprecipitated proteins; anti-Myc, Myc antibodies; anti-BAK1, BAK antibodies. 

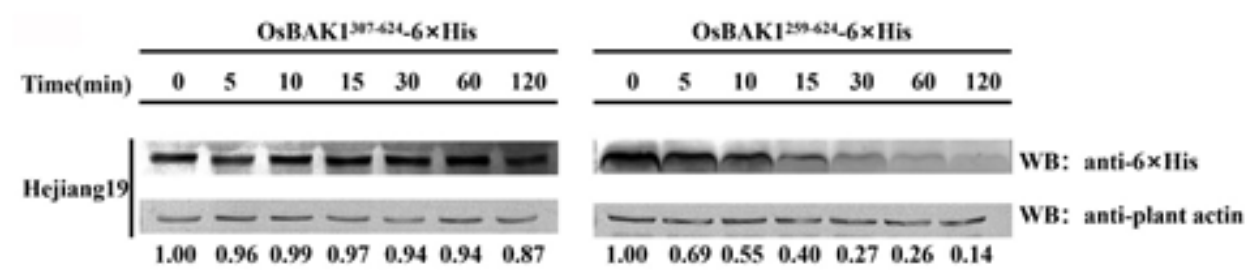

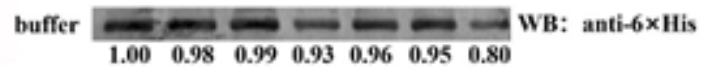

B

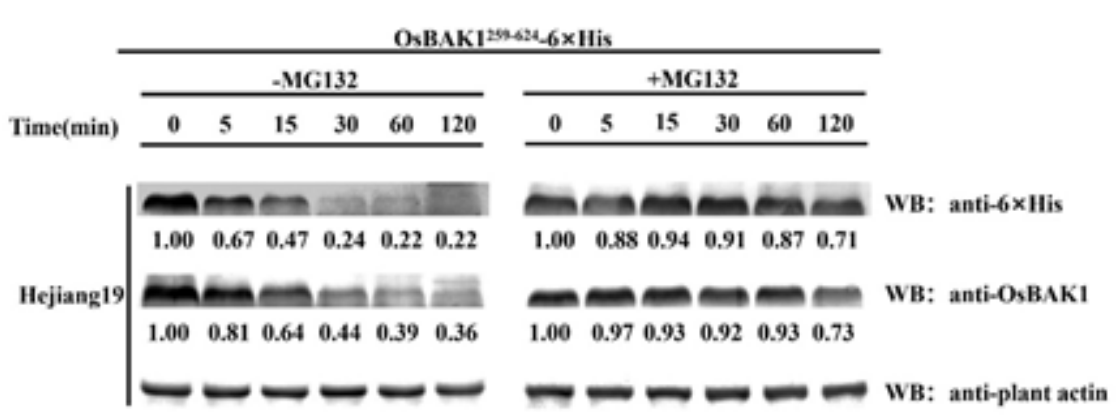

Figure 7

OsBAK $1^{259-624}$ protein was degraded in an OsWDRP3-dependent manner

A. OsBAK $1^{259-624}-6 \times$ His, but not OsBAK $1^{307-624}-6 \times$ His, degraded in an in vitro cell-free degradation assay.

B. In vitro cell-free degradation of OsBAK1 ${ }^{259-624}-6 \times$ His, which was incubated $(0,5,15,30,60$ and 120 min) in crude extracts from Hejiang 19, OsSWDRP3-RNAi and OsWDRP3-OE cells. MG132 treatment inhibited the degradation of OsBAK1 ${ }^{259-624-6 \times \text { His. }}$ 
C. In vitro cell-free degradation of OsBAK1 ${ }^{259-624-6 \times H i s, ~ w h i c h ~ w a s ~ i n c u b a t e d ~}(0,5,15,30,60$ and 120 min) in crude extracts from Hejiang 19 when OsWDRP3-6xHis was added.

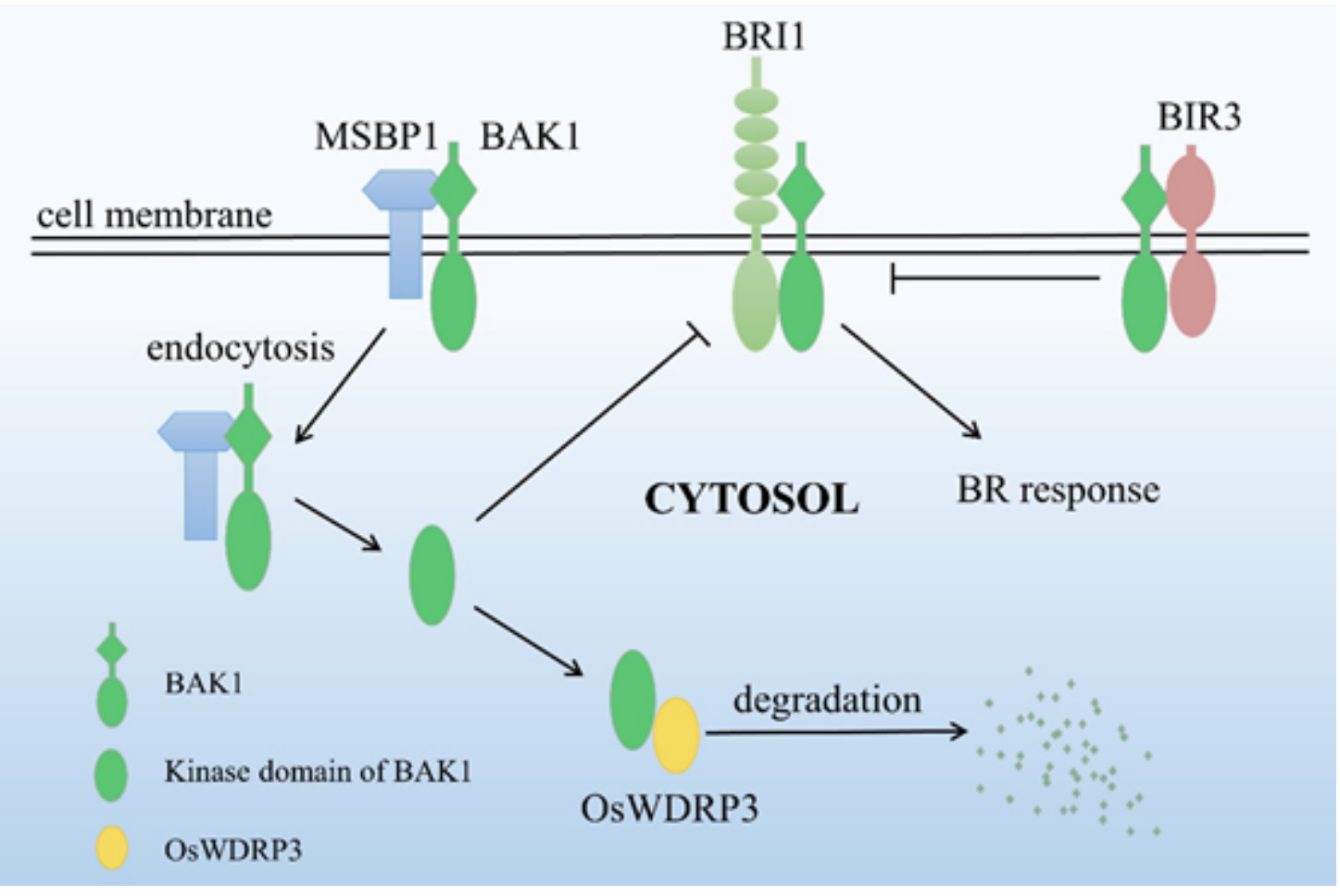

Figure 8

Diagram of OsWDRP3 regulating BR signaling by degrading OsBAK1 